\title{
Superstition and Perceived Stress of the Chinese and the Moderation of Self-efficacy
}

\author{
Zhong Sheng ${ }^{1, a}$ \\ ${ }^{1}$ Department of Applied Psychology, Soochow University, suzhou, jiangsu 215000, China \\ a ShengZhong1110@outlook.com
}

\begin{abstract}
Superstition, which gives rise to a series of erroneous beliefs, has long been a cross-cultural phenomenon, and it occurs more often in times of stress or uncertainty. The present study focused on the association between perceived stress and superstition of Chinese undergraduates and postgraduates, and explored whether self-efficacy plays the moderating role. We recruited 228 participants (Mean age $=21.18,134$ were female) to complete the Superstitious Beliefs Questionnaire (SBQ), Perceived Stress Scale (PSS) and General Self-efficacy Scale (SES). The results illustrated that superstition was positively correlated with perceived stress $(r=0.16, p<0.05)$, and its association with self-efficacy was negative, without reaching statistical significance $(r=-0.04, p>0.05)$. According to the regression analysis, the interaction of PSS and SES could hardly predict the superstitious belief $(B=0.02, t=0.87, p>0.05)$. In conclusion, from the statistical perspective, self-efficacy didn't have a significant moderating effect on the relationship.
\end{abstract}

Keywords: superstition, perceived stress, self-efficacy, moderating role.

\section{INTRODUCTION}

Superstition exists almost in every cultural background and it means that people who hold superstitious beliefs would like to hold some erroneous opinions[1], or a series of paranormal beliefs[2]. Early researchers viewed superstition as the attribution of naturally explainable phenomenon to mystical or paranormal causes, or making some false beliefs seem scientific[3]. Behavioristic psychologists convinced that, related to associative learning, superstition exists due to accidental enforcement of the cause and outcome, which is based on instrumental conditioning theory[4-6] as people tend to be sensitive to even small variation in contingency[7]. While from observational learning theory, superstitious beliefs could be learned through observation when some causality happened. Moreover, superstition was defined as a cognitive distortion, which led to the erroneous beliefs that one could affect the outcome of chance events[8,9]in cognitive psychology.

The form of superstition varies from different cultures[10]. In western countries, superstition beliefs are always associative with paranormal phenomenon or magic thinking, such as astrology, extrasensory perception, spirituality and precognition[11]. While in China, research on superstition mainly focuses on the fields of sociology, folklore, or politics. And most of the supernatural beliefs or behaviors are based on the deeprooted traditional Chinese culture, ritual and religion. Taking Taoism for example, Feng Shui, which aims at achieving balance between environment and health or fortune, plays a vital role in construction or business industry in China[12].

\subsection{Superstition and stress}

With the even severe competition nowadays, there has been a consistent increase of self-perceived stress among college students[13]. Superstitious beliefs occur especially when people feel stressful, challenged, and uncertain, because people are common to lose a sense of control under these circumstances[14,15]. College students exhibited more superstitious behaviors before tough examinations or athletic competitions than unimportant tests[16]. What's more, Lu et al found that, confronted with the unknown risk such as diseases, paranormal beliefs significantly predict higher vaccine uptake intention[17].

Previous research showed that superstition seems plausible to eliminate boredom proneness which is negatively associated with life purpose and perceived meaning[18], thus enhancing our sense of life control. Hence superstition is beneficial when it comes to 
providing us with judgement of control[19,20], in accordance with previous founding that superstition satisfies the needs of managing psychosocial stress[2,15]

\subsection{Superstition and self-efficacy}

Self-efficacy is identified in Social Cognitive Theory, defined as the personal appraisal of their abilities to overcome tough or challenging situations through specific performance[21]. Our thoughts and actions can be influenced by self-efficacy. It could be attempting to assume that people with low self-efficacy lack sense of control when they encounter obstacles or bear pressure, thus seeking security by means of superstition. A research found that luck-related superstition increased selfefficacy[22]. Through exploring the relationship of paranormal thoughts and general self-efficacy among Chinese university students, Wang deemed that selfefficacy was negatively correlated to their extent of superstition[23], which was consistent with that of Tobacyk and Shrader in 1991. However, Sachs mentioned that people with high self-efficacy were less superstitious, but not at a significant level[24].

In conclusion, superstition occurs more frequently when people feel stressful, and negatively associates with self-efficacy, but at ambiguous degree. However, there were no manifest association between the superstitious beliefs and certain emotional perceptions, namely, depression, anxiety, or stress[11]. Hence, as shown in Figure 1, the study will delve into the way perceived stress connected with superstition, and hypothesize that self-efficacy moderates the association.

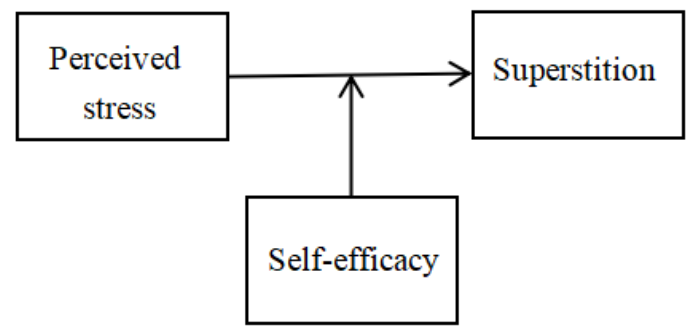

Figure 1. The moderation model of perceived stress, superstition and self-efficacy

\section{METHODS}

\subsection{Participants}

I recruited 228 participants (mean age $=21.18,134$ were female), and the data of 12 subjects who failed to pass the polygraph test (e.g., " Please choose strongly agree on this item.")were omitted. All the participants were college students ( 25 freshmen; 70 sophomores; 58 juniors; 49 seniors; 14 graduate or doctoral students). An online platform called Wenjuanxing in mainland China was used to fill in the questionnaires.

\subsection{Procedure}

Superstitious Beliefs Questionnaire was translated and modified based on the Chinese culture. Then Professor Robin Murphy, who developed the initial version of SBQ, provided some valuable suggestions about the adjusted items. Afterwards, participants around China were recruited online to complete the questionnaires.

\subsection{Materials}

\subsubsection{Superstitious Beliefs Questionnaire}

A previous Superstitious Beliefs Questionnaire has been translated and modified[11] (Cronbach's $\alpha=0.9$ ) as it hasn't been used in China before and some statements may not in line with Chinese culture and cognitive pattern. For example, item 6 was 'I would be uncomfortable with taking long trips on a Black Friday (the conjunction of a Friday and the 13th of any month)', and it has been changed into 'I would be uncomfortable with taking long trips on the 1st and 15 th of every lunar month(e.g., The Ghost Festival)'. Considering that hardly do a host of Chinese citizens know much about the Black Friday, similarly, they taboo taking long trips on the 2 days of every lunar month as Chinese legend has it that the days are when the disembodied spirits come to the world (The Ghost Festival is on the 15th of the seventh lunar month).

\subsubsection{The Perceived Stress Scale}

In order to estimate the level of perceived stress, the 14-item version the Perceived Stress Scale (PSS-14) was applied[25] (Cohen, Kamarck, \& Mermelstein,1983). Each stress manifestation was scored on a 5-point Likert scale, (" $1=$ never" "and " 5 = very often"), ranging from 14 to 70 on aggregate. It showed a strong internal consistency ( Cronbach's $\alpha=0.85$ ).

\subsubsection{The General Perceived Self-efficacy Scale}

Wang et al (2001) translated and modified the original 10 -item version of the General Perceived Self-efficacy Scale (GSES)[26]. It was a 4-point scale, (" $1=$ totally disagree" and " $5=$ totally agree"). Its internal consistency was .91 in present study .

\section{RESULTS}

\subsection{Analysis of Chinese Superstitios Beliefs Questionnaire}

The SBQ showed encouraging reliability among Chinese college students, Cronbach's a $=0.92$. An exploratory principal components analysis was of necessity to checkout the potential factor structure of the 
Chinese Superstitious Beliefs Questionnaire. The Kaiser-Meyer-Olkin value was 0.89, well surpassing 0.6 , which was the recommended value[27]. In terms of Bartlett's test of sphericity[28], it also demonstrated a statistical significance $\left(V_{300}^{2}=2330.52, p<0.001\right)$. The SBQ possessed six components with eigenvalues exceeding 1.0 , accounting for $61.74 \%$ of the variance totally.

\subsection{Common method bias test}

In present study, anonymity, reverse scoring of some items and the design of 2 polygraph tests were required to eliminate the common method. Harman single factor test showed that 11 factors with characteristic root over 1 were extracted from exploratory factor analysis, and the maximum eigenvalue of the variance was $20.39 \%$ (< $40 \%$ ). Hence, common method bias didn't significantly exist.

\subsection{Demographic data and t-test analysis of $S B Q, P S S$ and $S E S$}

The mean score of SBQ was 52.18, higher than that of the British in previous study. Compared with 26.43 in Wang's research[23], subjects in present study revealed a bit higher self-efficacy $(M=27.18, S D=5.67)$. While the perceived pressure of all participants were moderate.

Table 1 vividly demonstrated the result from $t$-test that, compared with male, female students were significantly more superstitious, stressful as well as had relatively low self-efficacy $(t(214)=4.65, p<0.001)$. People who had siblings $(t(214)=2.55, p=0.01)$, grew up in urban $\operatorname{areas}(t(214)=1.98, p=0.05)$ or worked as student cadre $(t(214)=0.38, p=0.05)$ had higher level of self-efficacy. Moreover, the superstitious level rose significantly with the increase of the grades, $F(5,210)=$ $2.49, p<0.05$.

Table 1 Demographic Information and $t$-test Analysis

\begin{tabular}{|c|c|c|c|c|c|}
\hline Variable & & $\mathrm{N}$ & SBQ & SES & PSS \\
\hline \multirow[t]{4}{*}{ gender } & male & 82 & $48.55(18.05)$ & $29.37(5.82)$ & $39.34(8.34)$ \\
\hline & female & 134 & $54.41(14.26)$ & $25.84(5.16)$ & $42.63(7.51)$ \\
\hline & $t$ & & -2.50 & 4.65 & -2.99 \\
\hline & Sig. & & 0.01 & 0.00 & 0.00 \\
\hline \multirow[t]{4}{*}{ siblings } & yes & 109 & $53.22(16.08)$ & 27.91(5.89) & $40.75(8.56)$ \\
\hline & no & 107 & $50.39(15.88)$ & $25.90(5.06)$ & $42.47(6.81)$ \\
\hline & $t$ & & 1.25 & 2.55 & -1.53 \\
\hline & Sig. & & 0.21 & 0.01 & 0.13 \\
\hline \multirow[t]{4}{*}{ environment } & urban & 137 & $53.27(17.52)$ & 27.93(5.62) & 40.74(8.39) \\
\hline & rural & 79 & $51.08(14.34)$ & $26.41(5.64)$ & $42.03(7.55)$ \\
\hline & $t$ & & 1.00 & 1.98 & -1.18 \\
\hline & Sig. & & 0.32 & 0.05 & 0.24 \\
\hline \multirow[t]{4}{*}{ Student cadre } & yes & 102 & $53.14(18.12)$ & $27.97(5.26)$ & $40.76(8.74)$ \\
\hline & no & 114 & $51.33(13.91)$ & $26.46(5.94)$ & $41.93(7.26)$ \\
\hline & $t$ & & 0.81 & 0.38 & -1.07 \\
\hline & Sig. & & 0.42 & 0.05 & 0.29 \\
\hline \multirow[t]{4}{*}{ religion } & yes & 14 & $56.5(14.20)$ & $26(4.67)$ & $41.93(7.94)$ \\
\hline & no & 202 & $51.89(16.13)$ & $27.26(5.73)$ & $41.34(8.02)$ \\
\hline & $t$ & & 1.04 & -0.80 & 0.27 \\
\hline & Sig. & & 0.30 & 0.42 & 0.79 \\
\hline \multirow[t]{2}{*}{ grade } & $F$ & & 2.49 & 2.11 & 0.84 \\
\hline & Sig. & & 0.03 & 0.06 & 0.53 \\
\hline$M(S D)$ & & & $52.18(16.03)$ & 27.18(5.67) & $41.38(7.99)$ \\
\hline
\end{tabular}

Note. SBQ = Superstitious beliefs Questionnaire; PSS = Perceived Stress Scale; SES = General Self-efficacy Scale. 


\subsection{Correlation analysis of the scores of $S B Q$, PSS and SES}

Table 2 revealed the Pearson correlation that the level of perceived stress was positively correlated with the level of $\operatorname{superstition}(r=0.16, p<0.05)$. The level of selfefficacy was negatively correlated with SBQ, without reach statistical significance $(r=-0.04, p>0.05)$. While the score of SES significantly correlated with $\operatorname{PSS}(r=$ $0.63, p<0.01)$, more perceived stress, less self-efficacy.

Table 2 Correlation of SBQ, PSS and SES

\begin{tabular}{|l|l|l|l|}
\hline & SBQ & PSS & SES \\
\hline BSQ & 1 & & \\
\hline PSS & $0.16^{*}$ & 1 & \\
\hline SES & -0.04 & $-0.63^{* *}$ & 1 \\
\hline
\end{tabular}

Note. SBQ = Superstitious beliefs Questionnaire; PSS = Perceived Stress Scale (14-item); SES = General Selfefficacy Scale. ${ }^{*} p<0.05 ; * * p<0.01$.

\subsection{The moderation analysis of self-efficacy}

To further investigate the association between perceived stress, self-efficacy and superstitious beliefs, especially whether if self-efficacy played a moderating role on stress and superstition, a regression analysis was conducted. As illustrated in table 3, PSS significantly predicted SBQ $(B=0.22, t=2.49, p<0.01)$, while SES did not closely associated with SBQ $(B=0.13, t=1.49, p$ $>0.05)$. Additionally, self-efficacy didn't moderate the relationship between PSS and SBQ to a statistically significant level as the interaction of PSS and SES could hardly predict the superstitious belief ( $B=0.02, t=0.87$, $p>0.05)$. And Figure 2 could vividly show the relationship through the simple slope test.

Table 3 Superstition Regressed on PSS and SES, including 3 Demographic Factors and Interaction

\begin{tabular}{|c|c|c|c|c|c|c|}
\hline & $R$ & $R^{2}$ & $F$ & $B$ & $t$ & Sig. \\
\hline Model 1 & 0.21 & $4.4 \%$ & 3.25 & & & 0.02 \\
\hline gender & & & & 0.39 & 2.79 & 0.01 \\
\hline environment & & & & -0.15 & -1.01 & 0.32 \\
\hline siblings & & & & -0.12 & -0.83 & 0.41 \\
\hline Model 2 & 0.27 & $7.5 \%$ & 3.40 & & & 0.03 \\
\hline gender & & & & 0.38 & 2.66 & 0.01 \\
\hline environment & & & & -0.15 & -1.01 & 0.32 \\
\hline siblings & & & & -0.12 & -0.83 & 0.41 \\
\hline PSS & & & & 0.23 & 2.65 & 0.01 \\
\hline SES & & & & 0.14 & 1.57 & 0.12 \\
\hline Model 3 & 0.28 & $7.8 \%$ & 2.96 & & & 0.38 \\
\hline Gender & & & & 0.37 & 2.58 & 0.01 \\
\hline environment & & & & -0.16 & -1.08 & 0.28 \\
\hline siblings & & & & -0.12 & -0.85 & 0.40 \\
\hline PSS & & & & 0.22 & 2.49 & 0.01 \\
\hline SES & & & & 0.13 & 1.49 & 0.14 \\
\hline PSS $\times S E S$ & & & & 0.02 & 0.87 & 0.38 \\
\hline
\end{tabular}

Note. SBQ = Superstitious beliefs Questionnaire; PSS = Perceived Stress Scale (14-item); SES = General Selfefficacy Scale. 


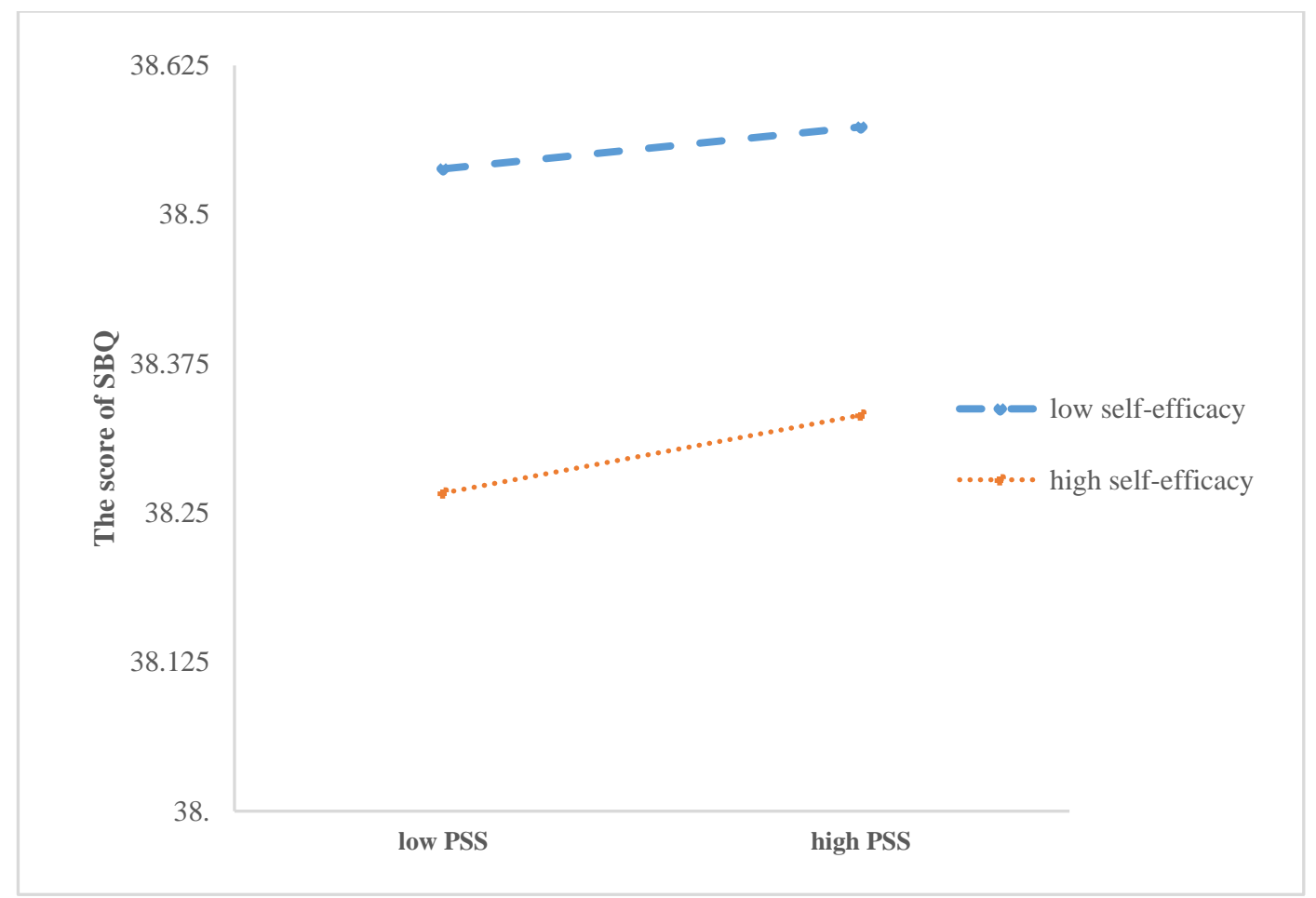

Figure 2. The Simple Slope Test of Perceived Stress and Self-efficacy on SBQ

Note. The figure illustrated the students with high or low self-efficacy’s SBQ score in high perceived stressful condition and low stressful condition.

\section{DISCUSSION}

\subsection{Evaluation of the modified Superstitious Beliefs Questionnaire}

Although the questionnaire is translated and some items were modified, the Chinese SBQ possesses satisfactory and dependable reliability and validity. The results and ideal property of the scale could basically reflect the superstitious degree of Chinese students with approximately normally distribution.

\subsection{Demographic variables and superstitious beliefs}

The general superstitious level of Chinese college students slightly exceeded that of British students in previous study ${ }^{[11]}$. It reflects that superstition of Chinese college students cannot be ignored. Superstition plays an even fundamental role in their life to deal with tough academic workload and heavy burden [23].

Similar to the results of previous studies, there's a possible gender difference in superstitiousness, and girls were more superstitious than boys[22,29]. The reasons can boil down to the following factors. First of all, males play the dominant role in many fields conventionally, such as politics, business and military domain, therefore tremendous efforts should be made if women would like to strive for equal rights. And it paralleled with the conspicuously higher stress perception and lower self- efficacy in this study. For this reason, superstitious beliefs do help for women to gain psychological comfort and alleviate the pressure. Moreover, it may be the natural sensibility and intuitive way of thinking that make them pay more attention to the co-occurrences of certain cause and effect, although they are illusory.

Contrasted with participants of lower grades, the advanced and postgraduate students were more superstitious. With the increase of grades, more choices are to be made by the students, and almost all the consequences of their choice and future life are unforeknown. According to previous studies, uncertainty is the key factor that attributes to paranormal thinking.

\subsection{The relationship between superstition, perceived stress and self-efficacy}

Apart from positively being correlated with SBQ, perceived stress could even significantly predict the degree of SBQ, the reasons being explored. Under stressful conditions, people have a propensity to be anxious and uncertain, so they resort to different methods to alleviate distress. And paranormal thinking can provide them with the illusion of control, therefore they rely more on a form of "psychic" to regain perceived control[15]. Further, superstitious beliefs often increase in times of stress, which is consistent with previous study[30]. Lasikiewicz et al found that positive superstitions improve self-appraisal of performance 
through a 'lucky pen' experiment, in that aside from alleviating stress, the sense of mastery can enhance selfefficacy[15]. So less stressful people show high selfefficacy, which constitute an inverse proportional relationship.

The initial hypothesis seemed to be overturned by the discrepant results, as the endorsement of self-efficacy did not significantly moderate the relationship of SBQ and PSS. Individual differences between the Chinese may provide an interpretation. For most people with high selfefficacy, they are generally more confident and possess judgement of control as they prefer positive internal attribution[23], so they do not rely too much on paranormal beliefs and behaviors to overcome challenging situations, which is often the case in previous research[31].

While for other people, according to the functional psychological theory, positive superstitions provide them with a shelter for psychological support, thus better adapting to the challenges in the context[22]. In Chinese culture, some religious or traditional theories have so deep-rooted effects on people's daily life that some of them are internalized as a part of their cognition. According to the data released by Chinese authority, approximately 200 million of Chinese have religious beliefs, most of them being buddhists and Taoists[32]. For instance, as a fundamental element in Taoism, people who believe in Feng Shui take up a moderate proportion in China. When they make important choice like which house to purchase, Feng Shui matters as it seems to bring long-term profits and well-being. Under such circumstances, laying emphasis to Feng Shui is rational even for people who refuse to acknowledge their superstition[12]. Some of the superstitious beliefs have been parts of their cognition and rationalized, without being realized. Consequently, fengshui, or some psychic actions are of equal importance when it comes to improving perceived-confidence and sense of control, thus enhancing self-efficacy.

Another interpretation is that superstitious people possess illusory causation both in action and interpretation, which attributes to their overestimate of conjunctive events[11]. Previous studies found that people with high paranormal beliefs avoid the repetition when generate randoms numbers, which showed that they systematically underestimated the possibility of a coincidence[33,34]. The cognitive bias and subjective avoidance make their spurious causal beliefs occur. So they tend to view certain accidental co-occurence as truth, which could enhance their sense of control instead. For example, if preying before an exam brings a student high scores, he may be more confident after preying in similar situation the next time.

\section{LIMITATION}

First of all, the number and age group of the participants were limited, so the Chinese version SBQ should be applied to more people to verify its validity. Moreover, through measuring by questionnaire, the uncertain degree of stressful situation was ambiguous. Further research will focus on manipulating the judgement of control by allocating participants to either stressful context or non-stressful context, such as a impromptu speech.

\section{CONCLUSION}

The current research investigates the relationship between perceived stress and superstition, and further explores if the moderation of self-efficacy is tenable. Contrary to prior hypothesis, although superstition was significantly correlated with stress perception and negatively related to self-efficacy to certain extent, the interaction of PSS and SES cannot significantly predict SBQ, which suggested that self-efficacy didn't play the moderating role on the relationship.

\section{ACKNOWLEDGMENTS}

I would like to sincerely acknowledge Professor Robin Murphy for his patient, professional guidance and instant feedback, as well as authorize me to translate and modify SBQ scale. I would also like to thank Christie Wang for her kind assistance during the process of the study.

\section{REFERENCES}

[1] Jahoda, G. . (1971). The psychology of superstition. allen lane.

[2] Irwin, H. J. (1993). Belief in the paranormal: A review of the empirical literature. Journal of the American Society for Psychical Research, 87(1), 139. doi:10.1007/BF01068157

[3] Rudski, J. (2003).What Does a "Superstitious" Person Believe? Impressions of Participants. The Journal of General Psychology(4), doi:10.1080/00221300309601168.

[4] Skinner, B. (1999). Science and human behavior. China Social Sciences Pub. House.

[5] Kevin R. Foster \& Hanna Kokko.(2009).The Evolution of Superstitious and Superstition-like Behaviour. Proceedings: Biological Sciences(1654).

[6] Abbott, K. R. , \& Sherratt, T. N . (2011). The evolution of superstition through optimal use of incomplete information. Animal Behaviour, 82(1), 85-92. doi:10.1016/j.anbehav. 2011. 04. 002. 
[7] Vallee-Tourangeau, F., Hollingsworth, L., \& Murphy, R. A. (1998). "Attentional bias" in correlation judgments? Smedslund (1963) revisited. Scandinavian Journal of Psychology, 39, 221233.https://doi.org/10.1111/1467-9450.00082.

[8] Joukhador, J., Blaszczynski, A. , \& Maccallum, F. (2004). Superstitious Beliefs in Gambling Among Problem and Non-Problem Gamblers: Preliminary Data. Journal of Gambling Studies(2),. doi:10.1023/B:JOGS.0000022308.27774.2b.

[9] Toneatto, T. (1999). Cognitive psychopathology of problem gambling. Substance Use and Misuse, 34, 1593-1604. doi:10.3109/10826089909039417.

[10] Bansal, S. B., Dixit, S., Waskel, B., Mahore, R. K., Mishra, S., \& Rokde, R. (2015). An observational study regarding prevalence of superstitious beliefs among patients admitted at a tertiary hospital in Indore. Journal of Evolution of Medical and Dental Sciences, 4, 3980-3985. https://doi.org/ $10.14260 /$ jemds/2015/57

[11] Oren, G. , Noor, S. , Murphy, R. A. , \& Le, P. . (2019). Superstition predicts perception of illusory control. British Journal of Psychology, 110.

[12] Peng, Y. S. , Hsiung, H. H. , \& Chen, K. H. (2012). The level of concern about feng shui in house purchasing: the impacts of self-efficacy, superstition, and the big five personality traits. Psychology \& Marketing, 29(7). doi:10.1002/mar.20539.

[13] Kerr, S., Johnson, V. K., Gans, S. E., \& Krumrine, J. (2004). Predicting adjustment during the transition to college: Alexithymia, perceived stress, and psychological symptoms. Journal of College Student Development, 45(6), 593-611. https://doi.org/10.1353/csd.2004.0068.

[14] Burger, J. M., \& Lynn, A. L.(2005).Superstitious Behavior Among American and Japanese Professional Baseball Players. Basic and Applied Social Psychology(1),. doi:10.1207/s15324834basp2701_7.

[15] Lasikiewicz, N. \& Wan, Y. T. (2018). The effect of superstitious thinking on psychosocial stress responses and perceived task performance. Asian Journal of Social Psychology, 21(1-2), pp. 32-41. doi:10.1111/ajsp.12195.

[16] Rudski, J. M., \& Edwards, A. (2007). Malinowski goes to college: Factors influencing students' use of ritual and superstition. The Journal of General Psychology, 134(4), 389403. doi:10.3200/GENP.134.4.389-404.

[17] Lu, J. H., Luo, M.Y., Yee, Z. H, Scheldenkar, A.,
Lau, J., \& Lwin, M. O. (2019). Do superstitious beliefs affect influenza vaccine uptake through shaping health beliefs?. Vaccine, 37(8), pp. 10461052. doi:10.1016/j.vaccine.2019.01.017.

[18] MacDonald, A. D. \& Holland, D. (2002). Spirituality and boredom proneness. Personality and Individual Differences, 32(6), pp. 11131119. doi:10.1016/S0191-8869(01)00114-3.

[19] Langer, E. J. (1975). The illusion of control. Journal of Personality and Social Psychology, 32, 311-328. doi:10.1037/0022-3514.32.2.311.

[20] Matute, H., \& Blanco, F. (2014). Reducing the illu sion of control when an action is followed by an undesired outcome. Psychonomic Bulletin \& Review, 21, 1087-1093. http://dx.doi.org/10.3758/s13423-014-0584-7

[21] Bandura, A. , Freeman, W. H. , \& Lightsey, R. . (1997). Self-efficacy: the exercise of control. Journal of Cognitive Psychotherapy.

[22] Kostovičová, L., Dudeková, K., \& Konečný, M. (2017). Vplyv iracionálneho presvedčenia na úspešnost'v riešení úloh u finančných profesionálov [The influence of irrational beliefs on problemsolving in financial professionals]. In I. Farka M. Takáč, J. Rybár, \& P. Gergel' (Eds.), Kognícia a umelý život 2017 [Cognition and artificial life 2017] (pp. 93-98).Bratislava, Slovakia: Comenius University.

[23] Wang, Q. F. (2011). Relationship between Attribution Mode, General Self-efficacy and Superstition of College Students. M. A. Thesis. Nanjing Normal University.

[24] Sachs, J.(2004). Superstition and Self-Efficacy in Chinese Postgraduate Students. Psychological Reports(2),. doi:10.2466/pr0.95.2.485-486.

[25] Cohen, S., Kamarck, T., \& Mermelstein, R. (1983). A global measure of perceived stress. Journal of Health And Social Behavior, 385-396. doi: $10.2307 / 2136404$

[26] Wang, C. K., Hu, Z. F., \& Liu, Y.(2001). Study on the reliability and validity of the general selfefficacy scale. Applied Psychology (01),37-40. doi: CNKI:SUN:YXNX.0.2001-01-006.

https://kns.cnki.net/KCMS/detail/detail.aspx?dbna me $=$ CMFD2012\&filename $=1011400554 . n h$.

[27] Kaiser, H. F., \& Rice, J. (1974). Little jiffy, mark IV. Educational and Psychological Measurement, 34(1), 111-117. https://doi.org/10.1177/001316447403400115.

[28] Bartlett, M. S. (1954). A note on the multiplying 
factors for various $X^{2}$ approximations.Journal of the Royal Statistical Society B, 16, 296-298. doi: 10.1111/j.2517-6161.1954.tb00174.x

[29] Zebb, B. J., \& Moore, M. C.(2003). Superstitiousness and perceived anxiety control as predictors of psychological distress. Journal of Anxiety Disorders(1), . doi:10.1016/S08876185(02)00176-7.

[30] Keinan, G. (2002). The effects of stress and desire for control on superstitious behavior. Personality and Social Psychology Bulletin, 28(1), 102-108. doi: 10.1177/0146167202281009

[31] Tobacyk, J \& Shrader, D.(1991).Superstition and Self-Efficacy. Psychological Reports(3_suppl),. doi:10.2466/pr0.1991.68.3c.1387.

[32] The Stats Council Information Office of the People's Republic of China. (2018). China's Policies and Practices on Protecting Freedo m of Religious Belief. Chinese Catholicism, 192(02), 7-12.

[33] Brugger, P., Landis, T., \& Regard, M. (1990). A sheep goat effect in repetition avoidance extrasensory perception as an effect of subjectiveprobability. British Journal of Psychology, 81, 455$468 . \quad$ https://doi.org/10.1111/j.20448295.1990.tb02372.x

[34] Mohr, C., Koutrakis, N., \& Kuhn, G. (2015). Priming psychic and conjuring abilities of a magic demonstration inflfluences event interpretation and random number generation biases. Frontiers in Psychology, 5, 1542. 